\title{
ABRIR MÃO, BATER CABEÇA OU PÔR AS BARBAS DE MOLHO? PRODUTIVIDADE FRASEOLÓGICA DO AGRUPAMENTO PARTES DO CORPO EM UM CORPUS SOBRE POLÍTICA
}

\author{
ABRIR MÃO, BATER CABEÇA OU PÔR AS BARBAS DE MOLHO? \\ GROUP PHRASEOLOGICAL PRODUCTIVITY BODY PARTS IN A CORPUS ON \\ POLITICS
}

\begin{abstract}
Davi Pereira de Sousa ${ }^{1}$
Abdelhak Razky ${ }^{2}$

Resumo: Este artigo, recorte da dissertação de Souza (2018), apresenta e descreve as sequências cristalizadas que se mostraram produtivas no agrupamento temático partes do corpo. $\mathrm{O}$ corpus da pesquisa foi organizado de forma semiautomática, usando-se o software WordSmith Tools, versão 5.0 (SCOTT, 2008). Teoricamente, segue-se a vertente francesa de Fraseologia, a partir de Mejri (1997, 1998, 2012). A distribuição das unidades em agrupamentos temáticos considera a orientação referencial como uma das possibilidades de cotejamento das expressões idiomáticas (ORTIZ ALVAREZ, 2000). Os resultados demonstram a ocorrência de 93 fraseologismos que fazem alusão a 26 partes do corpo, constituindo base para mecanismos semânticos.
\end{abstract}

Palavras-chave: fraseologia; discurso político; partes do corpo.

Abstract: This article analyses a sample corpus from Souza's dissertation (2018). It presents and describes the productive fixed lexical sequences related to the parts of the body. The corpus is organized by using the software WordSmith Tools, version 5.0 (SCOTT, 2008). Theoretically, it follows the French strand of Phraseology, starting from Mejri (1997, 1998, 2012). The distribution of the units in thematic groupings considers the referential orientation as one of the possibilities for the comparison of idiomatic expressions (ORTIZ ALVAREZ, 2000). The results demonstrate the occurrence of 93 phraseologisms that allude to 26 body parts, forming the basis for semantic mechanisms.

Keywords: phraseology; political speech; body parts.

\section{Introdução}

Este artigo constitui um recorte da dissertação de mestrado de Souza (2018), defendida no Programa de Pós-graduação em Letras da UFPA. A pesquisa está vinculada ao projeto Geossociolinguística e Socioterminologia - GeoLinTerm (RAZKY; LIMA; OLIVEIRA,

\footnotetext{
${ }^{1}$ Mestre e doutorando em Letras pela Universidade Federal do Pará (UFPA). Professor da Universidade Estadual do Pará (UEPA). Desenvolve pesquisas em Lexicologia, Terminologia, Socioterminologia, Fraseologia, Dialetologia e Sociolinguística. E-mail: davips312@gmail.com

${ }^{2}$ Graduado em Língua e Literatura Inglesa (Université Hassan II Casablanca), mestre e doutor em Linguística (Université de Toulouse Le Mirail). Professor do Programa de Pós-graduação em Letras da UFPA e do Departamento de Línguas Estrangeiras da UnB. Diretor do projeto Atlas Linguístico do Brasil e coordenador do grupo de pesquisa Geossociolinguística e socioterminologia. E-mail: arazky@gmail.com
} 
2010). Trata-se da primeira dissertação defendida no Norte do país no campo da Fraseologia, cujo objetivo geral consistiu em produzir um glossário de fraseologismos utilizados no discurso político, a partir do referencial teórico da vertente francesa da Fraseologia, sobretudo da perspectiva de Mejri (1997, 1998, 2012, 2018), e do instrumental metodológico da Linguística de Corpus (BERBER SARDINHA, 2004; TAGNIN, 2005, 2011).

O corpus da pesquisa é composto por 570 textos provenientes de blogs ou websites de 4 (quatro) colunistas que assinam matérias sobre política nas revistas Istoé, Época, Carta Capital e no jornal Folha de São Paulo, tendo sido escolhido um colunista por periódico ${ }^{3}$. Os textos foram publicados entre janeiro de 2014 e dezembro de 2016. Foram utilizados os softwares Words Smith Tools (SCOTTI, 2008), que realiza busca semiautomática em grandes corpora textuais, e o Lexique pro - versão 3.6 (SIL, 2004-2012), para preenchimento da ficha fraseológica de cada verbete, resultando posteriormente na organização do glossário, adotandose microestrutura formada por entrada, categoria gramatical, definição, contexto, variante fraseológica, remissiva e notas. Neste artigo, porém, objetiva-se especificamente apresentar e descrever as sequências cristalizadas que se mostraram produtivas no agrupamento temático partes do corpo. A distribuição das unidades em agrupamentos lexicais, no caso deste artigo, relativo a partes do corpo humano, considera a orientação referencial, mencionada por Ortiz Alvarez (2000) como uma das possibilidades de cotejamento das expressões idiomáticas. Desse modo, o critério da organização em agrupamentos lexicais depende da inclusão, nas sequências, de um ou mais elementos que fazem referência a determinado domínio. Os resultados demonstram a ocorrência de 93 fraseologismos, que, na sua composição sintagmática, fazem alusão a 26 partes diferentes do corpo, constituindo base para relações semânticas metonímicas e metafóricas.

$\mathrm{O}$ artigo está estruturado em três seções. A primeira seção constitui a introdução. A segunda, de natureza teórica, apresenta alguns conceitos básicos da Fraseologia, situa a problemática terminológica que caracteriza a área e discute os critérios utilizados na delimitação dos fraseologismos. Por fim, na terceira seção, apresentam-se os resultados

\footnotetext{
${ }^{3}$ Para selecionar os textos e as fontes a serem consultadas, estabeleceram-se os seguintes critérios: (i) os textos deveriam ter sido publicados entre janeiro de 2014 e dezembro de 2016; (ii) o colunista deveria estar vinculado a revistas/jornais de grande circulação no país; (iii) deveria ser, preferencialmente, engajado em discutir assuntos relacionados à política e; (iv) na medida do possível, representar ideologicamente uma ou mais tendência política, de direita, esquerda, centro etc. Ressalte-se que este último critério, pela dificuldade de aferir com precisão a orientação política do colunista, não foi utilizado como determinante para a seleção de um ou outro jornalista, embora os colunistas escolhidos expressem implícita e/ou explicitamente, nos textos, sua preferência ideológica. O corpus constituído possui as seguintes dimensões: 457, 217 tokens e 37, 188 types.
} 
alcançados, com foco no agrupamento temático das unidades a partir da orientação referencial apontada por Ortiz Alvarez (2000) e da noção de dupla estruturação semântica das sequências cristalizadas, discutida por Mejri (1997, 1998).

\section{Aporte teórico}

Nesta seção, discutem-se os principais conceitos da Fraseologia, à luz principalmente da vertente francesa, com destaque para os critérios utilizados para identificar e analisar as unidades fraseológicas. Aborda-se, também, brevemente, a questão terminológica que caracteriza a área.

\subsection{Fraseologia ou fraseologias?}

O termo fraseologia é polissêmico, sendo considerado, por vezes, controverso (cf. ORTIZ ALVAREZ, 2000; BARBOSA, 2012; MONTEIRO-PLANTIN, 2014). De modo geral, pode ser compreendido em pelo menos três acepções: a) unidade polilexical caracterizada, dentre outros critérios, por diferentes graus de fixidez sintática, restrições semânticas e frequência de uso; b) conjunto formado por essas unidades pertencentes ao uso geral de uma língua ou de um domínio especializado (fraseologia do português, fraseologia do futebol, fraseologia do meio ambiente); c) campo de estudo ou disciplina que tem tais unidades como objeto de investigação ${ }^{4}$. No entanto, tendo em vista os objetivos deste artigo ${ }^{5}$, o foco será dado à problemática que envolve a primeira acepção assinalada, com destaque para os critérios utilizados para identificar e delimitar as unidades fraseológicas.

Desse modo, para fins de exemplificação, constituem fraseologia, na acepção (a), sequências como a céu aberto (ao ar livre), armar um barraco (criar confusão, dar vexame ou fazer escândalo), bater o martelo (apresentar decisão final sobre determinada questão posta em debate). Elas são unidades polilexicais recorrentes na língua portuguesa, que apresentam distintos graus de fixidez sintática e semântica, idiomaticidade, restrições sintagmáticas e paradigmáticas, conforme se verá na seção de análise dessas propriedades. Ressalte-se, quanto à acepção de unidade polilexical, a existência de uma diversidade denominativa acentuada, que decorre evidentemente das diferentes afiliações teóricas e pontos de vista considerados, bem

\footnotetext{
${ }^{4}$ Costuma-se grafar a inicial maiúscula para referir à disciplina Fraseologia, distinguindo-se da grafia em letra inicial minúscula, relativa à fraseologia como unidade polilexical ou conjunto de sequências polilexicais características de uma língua ou de uma especialidade.

${ }^{5}$ Para uma discussão mais ampla sobre os desdobramentos das demais acepções observadas, conferir Souza (2018).
} 
como da ênfase dada ora a um aspecto da unidade (a fixidez, por exemplo), ora a outro, tal como a idiomaticidade. Ao realizar um levantamento dos principais termos utilizados como variantes dessas sequências polilexicais, Ortiz Alvarez (2012a) conclui que os mais frequentes são unidade fraseológica ${ }^{6}$ e fraseologismo, dentre as demais denominações, como expressão pluriverbal, unidade pluriverbal lexicalizada, expressão fixa, fraseolexema, frasema, combinatória lexical. Além destes termos, poderiam ser acrescentados, por exemplo: expressão idiomática, idiomatismo, expressão cristalizada etc.

Charles Bally (1951), considerado o "pai" da Fraseologia, ao tratar sobre a terceira possibilidade de se delimitar os fatos da expressão ${ }^{7}$, inclui sob o termo genérico phraséologie (fraseologia) as locuções compostas. Para ele, essas locuções constituem-se unidades lexicológicas e se caracterizam por serem formadas por várias palavras que, na combinação, perdem parte de seu significado usual para adquirirem um outro significado para a unidade resultante. $\mathrm{O}$ autor exemplifica o fenômeno com a expressão adverbial tout de suíte (imediatamente), em que não se manteve o significado de nenhum dos componentes da expressão.

Maurice Gross (1982), ao se referir a essas unidades polilexicais, utiliza os termos phrase, formes ou expressions figées (expressões fixas ou cristalizadas), os qualificadores proverbiales, idiomatiques, composées, méthapores e clichés. Segundo o autor, embora constituam fenômeno de envergadura, as expressões fixas foram por muito tempo ignoradas pelas teorias predominantes da Linguística, pela falta de estudos sistemáticos na área.

Por sua vez, Alberto Zuluaga (1980, p. 16) utiliza o termo unidade fraseológica para denominar "toda combinação fixa de palavras"8. Sob tal designação, o autor latino-americano reúne combinações linguísticas formadas por duas ou mais palavras em que haja fixidez, ilustrando com saudações do tipo: boa noite, feliz Páscoa etc. Observe-se, na definição referida por Zuluaga (1980), a ênfase dada ao aspecto da fixidez, uma das propriedades características dos fraseologismos. Já Ortiz Alvarez (2000, p. 73) define a fraseologia como a "combinação de elementos linguísticos de uma determinada língua, relacionados semântica e sintaticamente, que não pertencem a uma categoria gramatical específica e cujo significado é dado pelo conjunto de seus elementos". Para a autora, essas combinatórias são unidades semânticas que

\footnotetext{
${ }^{6}$ Segundo Pamies (2014), unidade fraseológica é o termo mais utilizado na Espanha.

${ }^{7}$ Para o autor, a terceira possibilidade de se delimitar os fatos da expressão ocorre quando "l'unité psychologique excede les limites de l'unité graphique et s'étend stir plusieurs mots” (BALLY, 1951, p. 5).

8 “[...] toda combinación fija de palabras" (ZULUAGA, 1980, p. 16).
} 
possuem traços categoriais próprios, distinguindo-se das palavras e das combinações livres, podendo-se, então, falar de "um sistema fraseológico da língua" (ORTIZ ALVAREZ, 2000, p. $75)$.

Monteiro-Plantin (2014) trata de unidades fraseológicas, entendendo-as como sequências linguísticas que integram o objeto de estudo da Fraseologia. Sob esta denominação, a autora inclui as sentenças proverbiais, expressões idiomáticas (EI), pragmatemas e fórmulas situacionais, colocações, locuções fixas, frases feitas, clichês e chavões. Ao definir as unidades fraseológicas, Corpas Pastor (1996) as considera unidades lexicais que constituem grupos de palavras, formadas por no mínimo duas palavras gráficas, podendo chegar ao nível das orações compostas ${ }^{9}$.

Ao criticar a profusão terminológica, a fim de se evitarem confusões teóricas, Salah Mejri (2012) propõe uma ordenação do campo terminológico da área, a partir da oposição entre o fenômeno fraseológico e o processo por meio do qual ele se exprime. Define, assim, a phraséologie (fraseologia) como fenômeno linguístico, comum a todas as línguas vivas, que se manifesta por meio das associações sintagmáticas recorrentes. Atua nesse fenômeno o processo de figement (cristalização, congelamento), do qual resultam os fraseologismos, que apresentam diferentes graus de fixidez, polilexicalidade, congruência, idiomaticidade e frequência de uso. Citam-se, como exemplos, "bater as botas", "sair de fininho", "quebrar um galho"10 , entre outros, cujos sentidos não provêm da mera somatória do significado individual dos componentes da estrutura complexa, mas trata-se de um sentido da unidade como um todo, em geral, de caráter idiomático, mas não apenas.

\subsection{A proposta de Salah Mejri para a identificação e delimitação de fraseologismos}

Ao assumir uma perspectiva lexical para o estudo do figement, integrando, no escopo da análise, aspectos da sintaxe, da semântica e da pragmática, Mejri (2012) propõe dois critérios fundamentais que, cruzados, permitem a delimitação de fraseologismos, diferenciando-os das sequências livres. Trata-se da fixidez e da congruência, vistas a partir da noção de continuum.

\footnotetext{
9 “[...] las unidades fraseológicas (UFS) - objeto de estudio de la fraseología - son unidades léxicas formadas por más de dos palabras gráficas en su límite inferior, cuyo límite superior se sitúa en el nivel de la oración compuesta" (CORPAS PASTOR, 1996, p. 20).

${ }^{10}$ Respectivamente: morrer, fugir discretamente de uma situação e dar uma ajuda a alguém em momento de necessidade.
} 
De acordo com Mejri (2012), a fixidez constitui uma nova noção que auxilia na descrição do processo de cristalização lexical pelo qual as sequências passam, em seus diferentes graus, em função do bloqueio que sofrem pelas regras da combinatória sintagmática. A fixidez pode atuar nos níveis sintático, semântico e pragmático, envolvendo tanto o eixo sintagmático quanto o eixo paradigmático.

No plano sintagmático, das associações, a fixidez sintática impede, por exemplo, determinadas alterações estruturais ${ }^{11}$ para fraseologismos como abrir mão e bater cabeça, que significam, respectivamente, desistir e preocupar-se ou ter dificuldade com algo ou alguém. Embora o verbo destas sequências admita a flexão nas diferentes pessoas do discurso, elas não aceitam a passivação (*a mão foi aberta; *a cabeça foi batida), nem o acréscimo de determinantes (*abrir a/uma mão; *bater a/uma cabeça), nem a modificação do nome por adjetivos (*abrir mão fria/grande/leve; *bater cabeça grande/pequena/inteligente), sob pena de a unidade deixar de ser usada como fraseologia. Ressalte-se, porém, a possibilidade do acréscimo de intensificadores na segunda sequência, mas não na primeira. Assim, é possível uma modificação como eles bateram muita cabeça com a prova de matemática, mas improvável uma forma como *eles abriram muita mão de seus sonhos.

Quanto ao nível semântico, são fixos no léxico os significados globais atribuídos a essas duas sequências referidas (desistir e preocupar-se), bem como aqueles referentes aos fraseologismos com a mão na massa e olho gordo. Para a primeira unidade (com a mão na massa), Houaiss (2009) registra o significado "em pleno ato", ao passo que o dicionário Aurélio (2004) registra "inveja, cobiça" para olho gordo. Esses significados são fixados no léxico e na cultura, sendo apreendidos globalmente, não resultando da soma individual dos significados das palavras que compõem as combinatórias.

No plano paradigmático, a fixidez atua no sentido de violar qualquer tipo de comutação que implique mudança de sentido para a sequência cristalizada. Por esse motivo, comutações dos componentes das sequências a seguir desfariam a natureza dos fraseologismos cara de pau (falta de vergonha, cinismo, pilantragem) e dar um tiro no pé (provocar uma ação cujo efeito prejudica a si próprio), como por exemplo: *rosto de pau, *cara de metal; *dar um tiro na mão/cabeça/boca, *dar uma bala no pé, *desferir um tiro no pé. No entanto, é preciso

\footnotetext{
${ }^{11}$ Os símbolos * (asterisco) e \pm , utilizados no início das sequências, indicam, respectivamente, que a reestruturação sintática (ou paradigmática) não é permitida pelas regras de congruência, ou que é possível que a reestruturação encontre respaldo no uso, em determinados contextos específicos.
} 
observar que, às vezes, a comutação paradigmática produz variantes fraseológicas ${ }^{12}$, mantendo o significado global da sequência, como as formas cara de madeira e tcometer um tiro no pé. Igualmente, a supressão de um componente pode resultar em outro fraseologismo, com estrutura e significado semelhantes, como a supressão do verbo dar na sequência referida, que produz a unidade fraseológica tiro no pé, definido por Correia \& Teixeira (2007, p. 437) como "fracasso; desilusão; fiasco".

Com base no critério da fixidez, o autor define a sequência cristalizada como a sequência que apresenta "uma fixidez total ou parcial das regras da combinatória sintagmática, da comutatividade paradigmática e da composicionalidade semântica” (MEJRI, 2012, p. 143)33. Percebe-se, portanto, nessa definição, a noção de grau como um pressuposto da fixidez. De fato, o fraseologismo botar a mão no fogo (por) - "não ter dúvida alguma a respeito da integridade, da competência e do caráter de (alguém)" ((HOUAISS, 2009) - permite a substituição do verbo "botar" pelo seu concorrente "pôr" (pôr a mão no fogo por), sem desfazer o significado da unidade.

Em relação à noção de congruência, o autor a define como "um processo de adaptação de unidades lexicais pelo qual elas se integram naturalmente na combinatória" (MEJRI, 2009, p. 79 apud MEJRI, 2012, p. 143). Tal adaptação ocorreria tanto no nível morfológico, sintático e semântico. Segundo o linguista, essa definição de congruência objetiva elaborar uma definição de palavra, cuja noção tem sido problemática há muito tempo na linguística.

No caso dos fraseologismos, a noção de congruência é pertinente pelo seu corolário, isto é, a incongruência, pela qual se considera que uma determinada sequência seja incongruente caso não atenda às regras que estão na base da formação das sequências cristalizadas (MEJRI, 2012). Concretamente, isso significa dizer, por exemplo, que a impossibilidade de se dizer *pelo(s) andar(es) da/de uma carruagem/carroça/automóvel se deve ao fato de a sintaxe cristalizada impor apenas pelo andar da carruagem, isto é, "do jeito que as coisas vão" (HOUAISS, 2009).

Para Mejri (2012), a noção de (in)congruência mostra-se relevante por possuir natureza distinta do conceito de gramaticalidade, que segundo ele, recai exclusivamente sobre a boa formação gramatical. Difere-se, ainda, da noção de aceitabilidade, de cunho normativo. Pelo contrário, a (in)congruência pode ser aplicada a todos os níveis da língua, especialmente na

\footnotetext{
${ }^{12}$ Mejri (2012) utiliza a noção de fixidez paradigmática total e parcial para explicar esses casos de variação fraseológica decorrente de comutação.
} 
sintaxe, semântica e pragmática. Com esse novo elemento metodológico, Mejri (2012) estabelece que tudo o que se encaixa nas regras da combinatória é considerado congruente, enquanto o que as contraria se torna incongruente.

Desse princípio, resulta a noção da previsibilidade. Define-se como previsível o que se espera de acordo com as "possibilidades inscritas na aplicação das regras" (MEJRI, 2012, p. 143). Este é um dos motivos que explica, por exemplo, o fato de os interlocutores completarem as sequências cristalizadas em caso de truncação, seja por qual razão for. Assim, para um falante do português brasileiro, cuja competência fraseológica lhe permita reconhecer e utilizar os fraseologismos da língua, não seria difícil prever a parte ausente da combinatória, completando a sequência tal como nos exemplos: antes só... do que mal acompanhado; mais vale um pássaro na mão... do que dois voando; nem que a vaca... tussa.

Observa o autor que a tripla característica das sequências cristalizadas favorece a previsibilidade sintagmática, ou seja, o fato de serem polilexicais, bem formadas e fixas. Por esse motivo, é possível que o falante realize a mesma operação de completar ou corrigir a sequência, seja em relação a uma unidade frástica, como o provérbio, seja se tratando de colocações, especializadas ou de uso na língua geral. No discurso especializado, por exemplo, as restrições paradigmáticas atuam de forma muito intensa, o que está relacionado evidentemente à tendência das comunicações especializadas serem normalmente forjadas para serem muito precisas, pois designam conceitos distintos na estrutura de conhecimento de um determinado domínio. Na política, por exemplo, um governo é governo de direita/de esquerda/de centro etc.

Da mesma forma, a incongruência também se verifica no plano pragmático, ao contrariar, por exemplo, as regras estabelecidas para a adequação entre as fórmulas e o contexto de enunciação. Assim, empregar indistintamente os pragmatemas boa noite e bom dia violaria as normas pragmáticas.

De acordo com o autor, o cruzamento das noções de fixidez e de (in)congruência permite a delimitação das sequências cristalizadas e, consequentemente, sua diferenciação em relação às combinatórias livres. Com efeito, as incongruências podem mensurar o grau de cristalização da sequência, em seu aspecto sintático, semântico e pragmático.

\section{Resultados e discussão}


Nesta seção, apresentam-se e discutem-se os resultados alcançados na pesquisa de Souza (2018), cujo recorte aqui realizado focaliza os fraseologismos agrupados ao conjunto temático corpo humano. Assim, do glossário produzido na dissertação, composto por 438 entradas, serão apresentados e discutidos apenas os 93 fraseologismos que aludem ao corpo humano.

\subsection{Quanto à noção de agrupamento temático}

Convém observar que, neste artigo, os fraseologismos foram organizados em agrupamentos temáticos com base na orientação referencial apontada por Ortiz Alvarez (2000) para o cotejamento de expressões idiomáticas ${ }^{13}$. Desse modo, o critério da organização em agrupamentos temáticos depende da inclusão, nas sequências, de um ou mais elementos que fazem referência a determinado domínio. Por esse motivo, unidades como abrir mão, bater cabeça e pôr as barbas de molho foram reunidas no conjunto temático que alude ao corpo humano. A adoção desta orientação referencial justifica-se, neste trabalho, apenas para efeito de uma primeira forma de sistematização das unidades fraseológicas analisadas, tendo em vista a produtividade do agrupamento corpo humano nas sequências cristalizadas extraídas do corpus de estudo.

Em outras palavras, o presente trabalho não nega o fato de o fraseologismo comumente apresentar um significado global, em geral opaco, o que exigiria um tratamento semântico mais adequado à sua natureza idiomática, conforme defendem Ortiz Alvarez (2000) e Fulgêncio (2014). Contudo, para os objetivos deste artigo, a sistematização por agrupamentos temáticos mostrou-se útil, pois permitiu demonstrar, de uma maneira geral, a produtividade do agrupamento corpo humano como base de referência para a criação e uso de fraseologismos. Além disso, conforme ressalta Mejri (1997, 1998), as sequências cristalizadas possuem uma dupla estrutura semântica, que possibilita dois tipos de decodificação, sendo um o mais frequentemente utilizado, baseado no significado global da sequência, e o outro que recupera os significados individuais dos componentes lexicais da combinatória. Segundo o autor, este último caso é sempre possível, uma vez que o fraseologismo possui uma espécie de memória lexical (MEJRI, 1997, 1998).

\footnotetext{
${ }^{13}$ A autora distingue ainda uma orientação semântica, a qual "engloba uma organização em torno de um conceito mais geral e abrangente e que sugere uma interpretação semântica das Eis (habilidade/ inteligência; ignorância/ conhecimento, etc.)" (ORTIZ ALVAREZ, 2000, p. 175). Ressalte-se que, no presente artigo, a análise engloba outras sequências polilexicais além da expressão idiomática.
} 
A seguir, exibe-se o gráfico 1, com o percentual de ocorrência dos fraseologismos coletados na pesquisa de mestrado, distribuídos em agrupamentos temáticos, como se vê:

Gráfico 1 - Distribuição geral dos fraseologismos em agrupamentos temáticos.

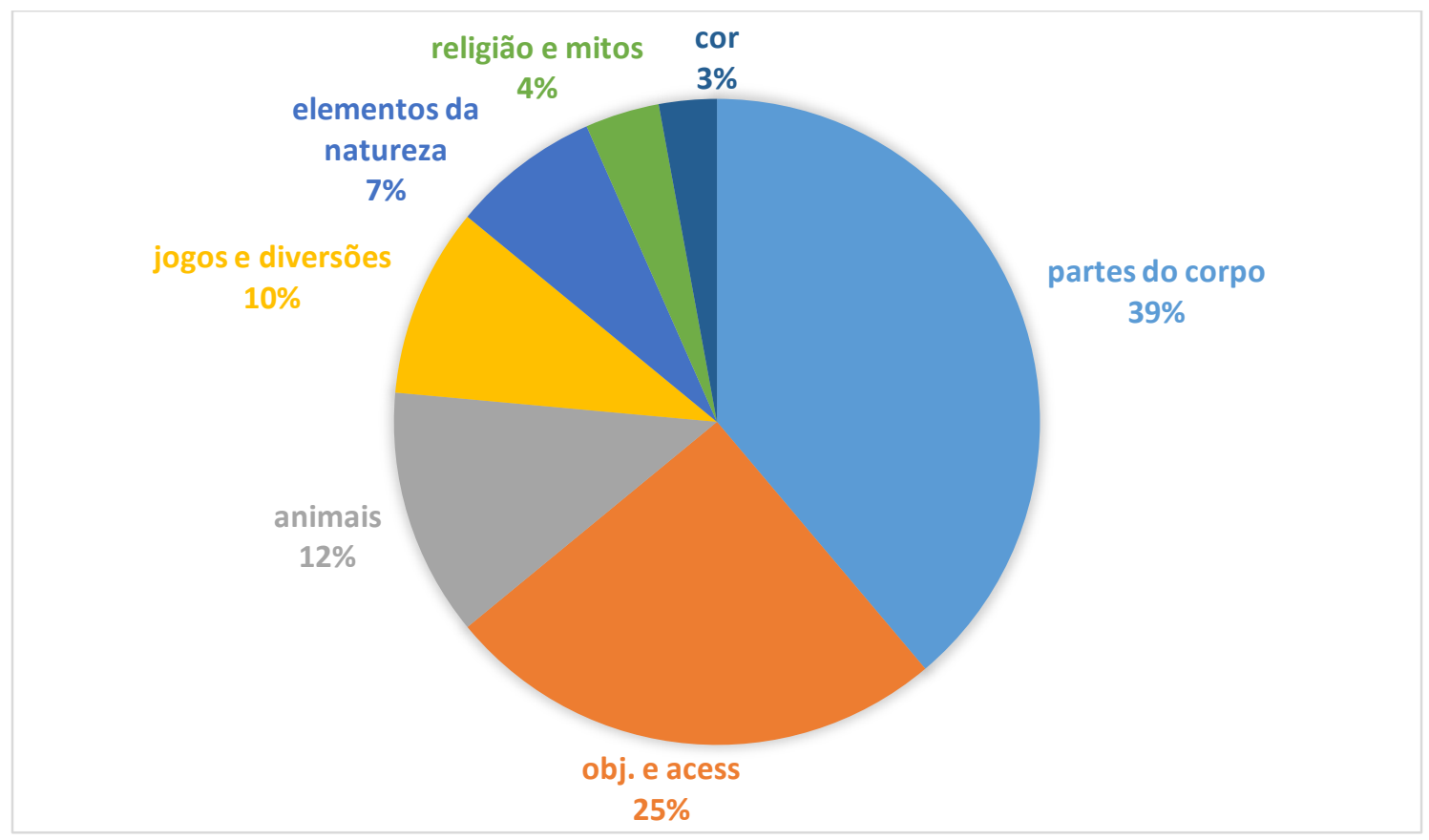

Fonte: Souza (2018, p. 126).

Curiosamente, o domínio partes do corpo contém a maior quantidade de fraseologismos dentre os demais agrupamentos temáticos. São 93 unidades que, na sua composição lexical, fazem alusão a 19 partes diferentes do corpo, como se vê na ilustração a seguir.

Ilustração 1 - Nomes relativos a partes do corpo que compõem fraseologismos. 
Fonte: Souza (2018, p. 126).

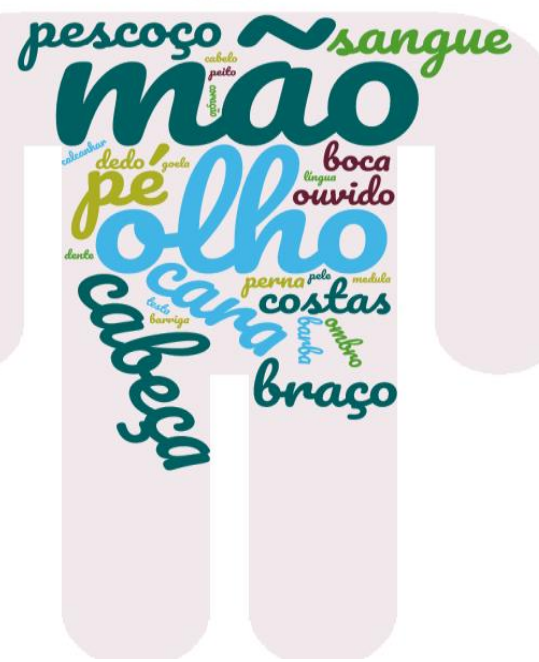

Do mais produtivo ao menos produtivo, o quadro abaixo reúne os substantivos que aludem ao corpo, com destaque para a palavra mão, que aparece como item lexical em 16 (dezesseis) fraseologismos.

Quadro 1 - Distribuição quantitativa dos fraseologismos segundo os nomes das partes do corpo.

\begin{tabular}{|c|c|c|c|}
\hline Item lexical & $\begin{array}{l}\text { Quantidade de } \\
\text { fraseologismo }\end{array}$ & Item lexical & $\begin{array}{ll}\text { Quantidade } & \text { de } \\
\text { fraseologismo } & \end{array}$ \\
\hline mão & 16 & ombro & 2 \\
\hline olho & 11 & perna & 2 \\
\hline cabeça & 8 & testa & 1 \\
\hline cara & 7 & pele & 1 \\
\hline Pé & 7 & língua & 1 \\
\hline pescoço & 5 & goela & 1 \\
\hline braço & 5 & barriga & 1 \\
\hline sangue & 5 & peito & 1 \\
\hline costas & 4 & coração & 1 \\
\hline boca & 3 & calcanhar & 1 \\
\hline
\end{tabular}




\begin{tabular}{|l|l|l|l|l|}
\hline ouvido & 3 & & cabelo & 1 \\
\cline { 1 - 1 } barba & 2 & & medula & 1 \\
\cline { 4 - 5 } dedo & 2 & dente & 1 \\
\cline { 4 - 5 } Total & $\mathbf{7 8}$ & & $\mathbf{1 5}$ \\
\hline \multicolumn{2}{|c|}{$\mathbf{9 3}$} \\
\hline
\end{tabular}

Fonte: Elaborado pelo autor.

As 5 (cinco) partes do corpo que se mostraram mais produtivas correspondem a $57 \%$ das unidades fraseológicas observadas, equivalentes a 49 (quarenta e nove) fraseologismos. Organizados em ordem decrescente, conforme a produtividade da parte do corpo cujo nome integra as sequências cristalizadas, os quadros abaixo apresentam as unidades e seus respectivos significados.

Quadro 2 - Fraseologismos com a palavra mão.

\begin{tabular}{|c|c|c|c|}
\hline FRASEOLOGISMO & SIGNIFICADO & FRASEOLOGISMO & SIGNIFICADO \\
\hline abrir mão & desistir de algo & jogar nas mãos de & $\begin{array}{l}\text { responsabilizar } \\
\text { indevidamente } \\
\text { alguém por } \\
\text { algum ato ou } \\
\text { medida }\end{array}$ \\
\hline botar a mão no fogo & $\begin{array}{l}\text { não ter dúvida } \\
\text { alguma a respeito } \\
\text { da integridade, } \\
\text { da competência e } \\
\text { do caráter de } \\
\text { (alguém) }\end{array}$ & lançar mão de & $\begin{array}{l}\text { Servir-se, } \\
\text { utilizar-se, valer- } \\
\text { se, de }\end{array}$ \\
\hline cair nas mãos de & $\begin{array}{lr}\text { passou a estar em } \\
\text { posse ou } & \text { sob } \\
\text { controle } & \text { de } \\
\text { alguém } & \\
\end{array}$ & meter a mão & $\begin{array}{l}\text { Cobrar preço } \\
\text { exorbitante }\end{array}$ \\
\hline com a mão na massa & em pleno ato & mão de ferro & $\begin{array}{l}\text { governo tirânico, } \\
\text { opressor }\end{array}$ \\
\hline $\begin{array}{l}\text { conhecer na palma da } \\
\text { mão }\end{array}$ & $\begin{array}{l}\text { ter conhecimento } \\
\text { preciso sobre } \\
\text { algo ou alguém }\end{array}$ & mãos à obra & $\begin{array}{lr}\text { atirar-se } & \text { com } \\
\text { afinco a r um } \\
\text { trabalho, a } \\
\text { atividade } & \\
\end{array}$ \\
\hline de mão beijada & $\begin{array}{l}\text { sem ter de } \\
\text { retribuir ou sem } \\
\text { nada receber em } \\
\text { troca }\end{array}$ & nas mãos de & $\begin{array}{l}\text { à mercê de; à } \\
\text { discrição de }\end{array}$ \\
\hline de mão em mão & $\begin{array}{lr}\begin{array}{l}\text { passando } \\
\text { pessoa } \\
\text { pessoa }\end{array} & \text { para } \\
\end{array}$ & \begin{tabular}{|llll}
$\begin{array}{l}\text { passar } \\
\text { cabeça }\end{array}$ & $a$ & mão & $n a$ \\
\end{tabular} & $\begin{array}{l}\text { desculpar, } \\
\text { relevar as faltas } \\
\text { de }\end{array}$ \\
\hline
\end{tabular}




\begin{tabular}{|l|l|l|l|l|}
\hline $\begin{array}{l}\text { fazer justiça pelas } \\
\text { próprias mãos }\end{array}$ & $\begin{array}{l}\text { vingar-se } \\
\text { pessoalmente de } \\
\text { mal cuja punição } \\
\text { caberia à justiça }\end{array}$ & pires na mão ${ }^{14}$ & pedindo esmola \\
\hline
\end{tabular}

Fonte: Elaborado pelo autor.

Como se vê, a palavra mão participa da composição de 16 fraseologismos, representando assim 19\% do total de unidades selecionadas para o agrupamento partes do corpo. Ela aparece, inclusive, duas vezes numa mesma sequência, como na unidade de mão em mão. Situação semelhante verificou-se nos fraseologismos com a palavra olho, sistematizadas no quadro abaixo.

Quadro 3 - Fraseologismos com a palavra olho.

\begin{tabular}{|c|c|c|c|}
\hline FRASEOLOGISMO & SIGNIFICADO & FRASEOLOGISMO & SIGNIFICADO \\
\hline de olho & $\begin{array}{l}\text { - desejoso, com } \\
\text { intentos sobre } \\
\text { (alguém ou algo } \\
\text { - em atitude de } \\
\text { vigilância ou de } \\
\text { cobiça }\end{array}$ & olho clínico & $\begin{array}{l}\text { compreensão } \\
\text { exata de uma } \\
\text { situação }\end{array}$ \\
\hline de olho aberto & $\begin{array}{l}\text { em atitude de } \\
\text { muita vigilância }\end{array}$ & olho gordo & inveja, cobiça \\
\hline de rabo de olho & espreitar & olho no olho & $\begin{array}{ll}\text { de forma } \\
\text { presencial, frente } \\
\text { a frente }\end{array}$ \\
\hline fechar os olhos & $\begin{array}{l}\text { fazer de conta } \\
\text { que não vê ou } \\
\text { não percebe }\end{array}$ & saltar aos olhos & $\begin{array}{l}\text { ser claro, } \\
\text { evidente, patente }\end{array}$ \\
\hline menina dos olhos & $\begin{array}{l}\text { pessoa ou coisa } \\
\text { que é objeto de } \\
\text { particular } \\
\text { consideração, } \\
\text { que é } \\
\text { especialmente } \\
\text { estimada }\end{array}$ & ver com bons olhos & $\begin{array}{l}\text { olhar } \quad \text { com } \\
\text { benevolência ou } \\
\text { satisfação }\end{array}$ \\
\hline $\begin{array}{l}\text { olhar com o rabo do } \\
\text { olho }\end{array}$ & olhar de esguelha & & \\
\hline
\end{tabular}

Fonte: Elaborado pelo autor.

Sendo a segunda palavra mais produtiva do agrupamento partes do corpo, a palavra olho compõe 11 (onze) fraseologismos, correspondendo a 13\% do total de unidades coletadas para esse domínio. Assim como a palavra mão, vista anteriormente, o item lexical olho também é utilizado mais de uma vez numa mesma sequência, como na unidade olho no olho. Nota-se,

\footnotetext{
${ }^{14}$ A forma completa do fraseologismo é "de pires na mão", conforme registrado no dicionário brasileiro de fraseologia (SILVA, 2013).
} 
também, a ocorrência de variante conceitual e denominativa em fraseologismos compostos por essa palavra. No primeiro caso, trata-se da variação conceitual observada pela existência de duas acepções registradas para o fraseologismo de olho. Com a acepção de desejoso, com intentos sobre (alguém ou algo), cita-se o seguinte contexto extraído do corpus sobre política: "<De olho na> turma, no voto da moçada e com uma missão a cumprir, ele [Fernando Haddad] reassumirá a cadeira de vereador, hoje com o ex-ministro do Esporte Orlando Silva" $(\text { RIRB14M1a })^{15}$. Na segunda acepção, isto é, em atitude de vigilância ou de cobiça, observa-se o uso do fraseologismo no excerto: "Continua a festa das fraudes e dos laranjas, mas o Tribunal de Contas da União e o Tribunal Superior Eleitoral estão < de olho> " (RERA16M9b).

No segundo caso de variação denominativa, percebe-se a ocorrência das variantes de rabo de olho e olhar com rabo de olho. Tal variação ilustra o caráter gradual da fixidez sintagmática e paradigmática, discutida por Mejri (2012), uma vez que se admite a supressão de parte da combinatória e o acréscimo de componentes, sem desfazer, contudo, a unidade como fraseologismo.

Quadro 4 - Fraseologismos com a palavra cabeça.

\begin{tabular}{|c|c|c|c|}
\hline FRASEOLOGISMO & SIGNIFICADO & FRASEOLOGISMO & SIGNIFICADO \\
\hline bater cabeça & $\begin{array}{l}\text { preocupar-se } \\
\text { com algo ou } \\
\text { alguém }\end{array}$ & mergulhar de cabeça & $\begin{array}{l}\text { dedicar-se } \\
\text { profundamente; } \\
\text { entregar-se com } \\
\text { toda a disposição }\end{array}$ \\
\hline de ponta-cabeça & $\begin{array}{l}\text { de cabeça para } \\
\text { baixo; de pernas } \\
\text { para o ar }\end{array}$ & $\begin{array}{llll}\text { passar } & a & \text { mão } & n a \\
\text { cabeça } & & & \end{array}$ & $\begin{array}{l}\text { desculpar, } \\
\text { relevar as faltas } \\
\text { de }\end{array}$ \\
\hline dor de cabeça & $\begin{array}{l}\text { preocupação, } \\
\text { problema }\end{array}$ & passar pela cabeça & $\begin{array}{l}\text { trazer (algo) à } \\
\text { memória; } \\
\text { lembrar-se, } \\
\text { ocorrer }\end{array}$ \\
\hline fazer a cabeça de & $\begin{array}{l}\text { convencer, levar } \\
\text { (alguém) a } \\
\text { modificar um } \\
\text { ponto de vista }\end{array}$ & pedir a cabeça & $\begin{array}{lr}\begin{array}{l}\text { solicitar } \\
\text { punição }\end{array} & \mathrm{a} \\
\text { alguém } & \mathrm{de}\end{array}$ \\
\hline
\end{tabular}

Fonte: Elaborado pelo autor.

\footnotetext{
15 Esta codificação foi feita nos textos que compõem o corpus para facilitar a identificação da fonte quando processados pelo software WordSmith Tools. A codificação consiste em: R para revista (ou J, no caso do Jornal) + Primeira letra do nome da revista ou jornal+ Iniciais do colunista + ano de publicação + mês + vogais para diferenciar as edições semanais. Assim, RIRB14M1a corresponde a uma coluna publicada na revista Istoé, assinada pelo colunista Ricardo Boechat, na primeira semana de janeiro do ano de 2014.
} 
Em terceiro lugar em termos de produtividade, a palavra cabeça compõe 8 (oito) fraseologismos, correspondendo a $9 \%$ das unidades coletadas.

Quadro 5 - Fraseologismos com as palavras cara e pé.

\begin{tabular}{|l|l|l|l|}
\hline \multicolumn{2}{|c|}{ CARA } & \multicolumn{2}{c|}{ PÉ } \\
\hline FRASEOLOGISMO & SIGNIFICADO & FRASEOLOGISMO & SIGNIFICADO \\
\hline cara de pau & $\begin{array}{l}\text { falta de vergonha; } \\
\text { caradurismo, } \\
\text { cinismo, pilantragem }\end{array}$ & ao pé da letra & $\begin{array}{l}\text { literalmente, em } \\
\text { sentido estrito, } \\
\text { rigorosamente }\end{array}$ \\
\hline${\text { cara lavada }{ }^{16}}^{\text {com }}$ & $\begin{array}{l}\text { transparência e } \\
\text { honestidade }\end{array}$ & ao pé do ouvido & $\begin{array}{l}\text { em segredo, de modo } \\
\text { discreto }\end{array}$ \\
\hline dar a cara a tapa & pôr-se à prova & bater o pé & $\begin{array}{l}\text { manifestar oposição; } \\
\text { agir de maneira } \\
\text { insistente }\end{array}$ \\
\hline $\begin{array}{l}\text { dar com a cara } \text { porta } \\
\text { na }\end{array}$ & não ser atendido & dar um tiro no pé & $\begin{array}{l}\text { provocar uma ação } \\
\text { cujo efeito prejudica } \\
\text { a si próprio }\end{array}$ \\
\hline dar na cara & $\begin{array}{l}\text { ser óbvio; estar } \\
\text { patente }\end{array}$ & de pé & $\begin{array}{l}\text { firme, sem se afastar } \\
\text { de situação ou ponto } \\
\text { de vista dantes } \\
\text { assumido }\end{array}$ \\
\hline livrar a cara & $\begin{array}{l}\text { tirar ou sair de } \\
\text { situação embaraçosa }\end{array}$ & tiro no pé & $\begin{array}{l}\text { fracasso; desilusão; } \\
\text { fiasco }\end{array}$ \\
\hline mostrar a cara & $\begin{array}{l}\text { revelar-se como } \\
\text { realmente é }\end{array}$ & um pé cá outro lá & $\begin{array}{l}\text { com extrema rapidez; } \\
\text { com a maior ligeireza } \\
\text { possível }\end{array}$ \\
\hline
\end{tabular}

Fonte: Elaborado pelo autor.

Por sua vez, as palavras cara e pé compõem, cada uma, 7 (sete) fraseologismos, respondendo, no total, por $16 \%$ das sequências arroladas no agrupamento temático corpo humano.

Os demais nomes relativos ao corpo correspondem a $43 \%$ dos fraseologismos, perfazendo um total de 44 (quarenta e quatro) unidades ${ }^{17}$. Em ordem decrescente, verificou-se: para pescoço (atolar-se até o pescoço, carne de pescoço, envolver-se até o pescoço, estar com a corda no pescoço, livrar o pescoço); para braço (braço direito, braço forte, cair nos braços de, cruzar os braços, queda de braço); para sangue (com gosto de sangue na boca, dar o sangue,

\footnotetext{
${ }^{16}$ A sequência <cara lavada> pode ser utilizada também como fraseologismo para indicar outro significado, servindo para qualificar uma pessoa dissimulada, sem vergonha.

${ }^{17}$ Como se trata apenas de um recorte da dissertação de Souza (2018), optou-se por apresentar, neste artigo, os significados dos fraseologismos agrupados em torno das cinco palavras mais produtivas (mão, olho, cabeça, cara e pé). Todavia, as demais unidades encontram-se devidamente registradas e definidas no glossário de fraseologismos no discurso político (SOUZA, 2018).
} 
ferver o sangue, irmão de sangue, Operação Sangue Negro); para costas (jogar nas costas, nas costas, virar as costas, virar as costas para); para boca (bater boca, com gosto de sangue na boca, morrer pela boca); para ouvido (ao pé do ouvido, as paredes têm ouvidos, dar ouvido a); para barba (nas barbas de, pôr as barbas de molho); para dedo (dar os anéis para conservar os dedos, ficar chupando o dedo); para ombro (carregar nos ombros, dar de ombros); para perna (bater pernas, perna de pau); para testa (testa de ferro); para pele (sentir na pele); para língua (sem papas na língua); para goela (meter goela abaixo); para barriga (empurrar com a barriga); para peito (do peito); para coração (cortar o coração); para calcanhar (calcanhar de aquiles); para cabelo (até a raiz dos cabelos); para medula (até a medula) e; para dente (armado até os dentes).

Algumas dessas sequências utilizam mais de um componente que faz referência ao corpo, razão por que constam tanto em um grupo quanto em outro. É o caso, por exemplo, de passar a mão na cabeça, ao pé do ouvido, com gosto de sangue na boca, dentre outros.

Nota-se, também, que, em determinados casos, a variante considerada mais informal possui preferência na produção de fraseologismos. No corpus de estudo, não se encontrou, por exemplo, nenhuma unidade fraseológica formada com a palavra rosto ${ }^{18}$. No entanto, a sua variante "cara" mostrou-se muito produtiva, constituindo 7 (sete) sequências cristalizadas (cara de pau, cara lavada, dar a cara a tapa, dar com a cara na porta, dar na cara, livrar a cara, mostrar a cara).

Em face do que foi exposto, percebe-se que muitos dos componentes nominais das unidades cristalizadas em questão, sobre as quais atuam mecanismos semânticos metafóricos e principalmente metonímicos, fazem referência ao agrupamento corpo humano, revelando-o produtivo. Esse modo de sistematização dos fraseologismos leva em conta a orientação referencial apontada por Ortiz (2000) para o estudo comparativo das expressões idiomáticas e, sobretudo, a compreensão de Mejri $(1997,1998)$ de que a sequência cristalizada possui uma memória lexical, sustentada por sua dupla estruturação semântica, que se constrói sobre a análise do sentido global da unidade, sem excluir totalmente a possibilidade de se acessar os sentidos literais das sequências, embora este tipo de análise não seja o mais comum no campo fraseológico.

\footnotetext{
${ }^{18}$ Deve-se ressaltar que essa observação diz respeito especificamente ao corpus utilizado, pois, na língua comum, há também uma infinidade de sequências cristalizadas com a palavra rosto. Silva (2013) registra, por exemplo: maçã do rosto, folha de rosto, amassar/ganhar o pão com o suor do rosto, lançar em rosto, ter o rosto liso como bundinha de nenê etc.
} 


\section{Considerações finais}

O presente artigo constitui um recorte da dissertação de Souza (2018), que produziu um glossário impresso e eletrônico de fraseologismos utilizados no discurso político. Objetivou-se aqui apenas demonstrar alguns exemplos das unidades fraseológicas coletadas no corpus de estudo, as quais foram organizadas, neste trabalho, para fins de sistematização, em agrupamento temático, mais especificamente no agrupamento relativo ao corpo humano.

Verificou-se que o referido agrupamento mostrou-se produtivo ao reunir 93 das unidades coletadas, com destaque para as palavras mão, olho, cabeça, cara e pé, que estão presentes na composição sintagmática de $57 \%$ das unidades fraseológicas observadas, equivalendo a 49 (quarenta e nove) fraseologismos.

Como se disse anteriormente, esse tipo de sistematização dos fraseologismos não nega a natureza geralmente não composicional do seu significado global. Aliás, em trabalho futuro, essas mesmas unidades serão analisadas sob uma orientação semântica, onomasiológica, para fins de comparação, a fim de se observar o distanciamento do significado global da sequência e a referência aos significados literais das palavras que compõem a combinatória.

\section{Referências}

BALLY, Charles. Traité de stylistique française. 2 ed. Paris: Klincksieck, 1951.

BARBOSA, M. A. A fraseologia no percurso gerativo de enunciação de codificação: no sistema, nas normas, no falar concreto. In: ORTIZ ALVAREZ, M. L. (org.). Tendências atuais na pesquisa descritiva e aplicada em fraseologia e paremiologia. V.1. Campinas, SP: Pontes Editores, 2012a.

BERBER SARDINHA, T. Lingüística de corpus. Barueri, SP: Editora Manole, 2004.

CORPAS PASTOR, G. Manual de fraseologia española. Madrid: Gredos, 1996.

CORREIA, Emanuel de Moura; TEIXEIRA, Persília de Merlim. Dicionário prático de locuções e expressões correntes. Santa Catarina: Papiro Editora, 2007. 
FERREIRA, Aurélio Buarque de Holanda. Novo dicionário eletrônico Aurélio. 3 ed. rev. atual. Curitiba: Editora Positivo. Versão 5.0, 2004.

FULGÊNCIO, Lúcia. Zoomorfismos, botanismos, gastronomismos: é assim que devem ser classificados os fraseologismos? Caligrama, Belo Horizonte, v.19, n.2, p. 179-196, 2014.

GROSS, M. Une classification des phrases figées du français. Revue québécoise de linguistique, v. 11, n. 2, 1982, pp. 151-185.

HOUAISS, A. Dicionário eletrônico Houaiss da língua portuguesa. Rio de Janeiro: Objetiva. Versão 3.0, 2009.

MEJRI, Salah. Le figement lexical: descriptions linguistiques et structuration sémantique. Tunis: Publications de la faculté des lettres de la Manouba, 1997.

Le figement lexical: descriptions linguistiques et structuration sémantique. In:

L'Information Grammaticale, n. 76, 1998, p. 50-51.

La memoire des sequences figees : une troisième articulation ou la réhabilitation du culturel dans le linguistique. Actes du colloque : La mémoire des mots. Actualité Scientifique, Tunis, AUPELF-UREF, pp. 3-11.

Délimitation des unités phraséologiques. In: ORTIZ ALVAREZ, M. L. (org.). Tendências atuais na pesquisa descritiva e aplicada em fraseologia e paremiologia. V.1. Campinas, SP: Pontes Editores, 2012a.

MONTEIRO-PLANTIN, R. S. Fraseologia: era uma vez um patinho feio no ensino de língua materna (volume I). Fortaleza: Imprensa Universitária, 2014.

ORTIZ ALVAREZ, M. L. Expressões idiomáticas do português do Brasil e do espanhol de Cuba: Estudo contrastivo e implicações para o ensino de português como língua estrangeira. 2000. 334f. Tese (Doutorado) - Universidade Estadual de Campinas, Instituto de Estudos da Linguagem. UNICAMP, Campinas, SP, 2000.

. (org.) Tendências atuais na pesquisa descritiva e aplicada em fraseologia e paremiologia. V.1. Campinas, SP: Pontes Editores, 2012a.

PAMIES, Antonio. A metáfora gramatical e as fronteiras (externas e internas) da fraseologia. Revista de Letras. no 33, v. 1 - jan./jun, p. 51-77, 2014.

RAZKY, A.; LIMA, A. F. de; OLIVEIRA, M. B. de. Geossociolinguística e Socioterminologia no Brasil - GeoLinTerm (projeto de pesquisa). UFPA, 2010. $19 \mathrm{f}$.

SILVA, José Pereira da. Dicionário brasileiro de fraseologia (versão preliminar). Rio de Janeiro: [s.n], 2013. 
SOUZA, Davi P. de. Fraseologismos no discurso político brasileiro: uma proposta de glossário. 2018. 249 f. Dissertação (Mestrado em Letras) - Universidade Federal do Pará. Belém, 2018.

SCOTT, M. WordSmith Tools, versão 5.0. Liverpool: Lexical Analysis Software, 2008.

TAGNIN, S. E. O. O jeito que a gente diz: expressões convencionais e idiomáticas. São Paulo: Disal, 2005.

Linguística de corpus e fraseologia: uma feita para a outra. In: ORTIZ ALVAREZ, M. L.; UNTERNBÄUMEN, Enrique H. (orgs.). Uma (re)visão da teoria e da pesquisa fraseológicas. Campinas, SP: Pontes Editores, 2011, p. 277-302.

ZULUAGA, A. Introducción al estudio de las expresiones fijas. Frankfurt: Verlag Peter D. Lang., 1980. 